\title{
CULTURA, RACIONALIDADE E POLÍTICA EM RICHARD RORTY: REFLEXÕES E RELAÇÕES COM A EDUCAÇÃO
}

\author{
Maria A. Lima Piai ${ }^{1}$ \\ Viviane Batista Carvalho ${ }^{2}$
}

\section{Resumo:}

Richard Rorty (1931-2007), filósofo norte-americano, tem sido considerado um importante representante do neopragmatismo. Seus escritos e estudos trazem contribuições relevantes para o debate e esclarecem pontos significativos para a reflexão sobre a produção cultural humana. Essas distinções são historicamente tratadas a partir de um projeto filosófico que é tradicionalmente dualista e idealista e platônico, o qual precisa ser combatido, na visão de Rorty (1994), por ser puramente dualista e contraditório. Essas distinções também têm marcado o campo das ciências, da política, das artes e da moralidade juntamente com a filosofia, uma vez que dizem respeito às ferramentas que o homem pode fabricar para resolver seus problemas e contribuir para o progresso social. Nesse sentido, este artigo tem por objetivo apresentar alguns aspectos da discussão feita pelo autor sobre a ideia de racionalidade e cultura e suas relações com os processos sociais/educativos na contemporaneidade buscando alcançar laços de convivência mais harmônicos na interação entre as culturas, as artes e política, contribuindo para o desenvolvimento e continuidade da sociedade humana.

PALAVRAS-CHAVE: Cultura. Educação. Racionalidade. Sociedade pós-moderna.

\section{CULTURE, RATIONALITY AND POLICY IN RICHARD RORTY: REFLECTIONS AND RELATIONS WITH EDUCATION}

\begin{abstract}
:
Richard Rorty (1931-2007), american philosopher, has been considered an important representative of neopragmatism. His writings and studies bring relevant contributions to debate and clarify significant points for reflection on human cultural production. These distinctions are historically treated under a philosophical projection that is traditionally dualistic and idealistic and Platonic, which needs to be fought, in the view of Rorty (1994), for being purely dualistic and contradictory. And these distinctions have also marked the field of science, politics, the arts and morality together with philosophy, since they concern the tools that man can manufacture to solve his problems and contribute to social progress. In this sense, this article aims to present some aspects of the discussion made by the author on the idea of rationality and culture and its relations with social / educational processes in contemporaneity seeking to achieve more harmonious bonds of coexistence in the interaction between cultures, in the art and politics contributing to the development and continuity of human society.
\end{abstract}

Keywords: Culture. Education. Rationality. Postmodern society.

\footnotetext{
${ }^{1}$ Maria A. Lima Piai: Professora da educação básica na rede privada e pública do estado do Paraná (SEED/PR) e professora na Universidade Estadual do Paraná/UNESPAR. É pesquisadora do grupo de pesquisa Filosofia, Educação e Condição Humana e do grupo de pesquisa A Educação Filosófica de Crianças, Adolescentes e Jovens da Universidade Estadual de Londrina. Possui licenciatura plena em Filosofia pela Universidade Estadual de Londrina (2002). É mestra em Educação pela Universidade Estadual de Londrina e doutora em Educação pela Universidade de São Paulo (USP). E-mail: maria-piai@ hotmail.com

${ }^{2}$ Viviane Batista Carvalho: Professora titular do Centro Municipal de Educação Infantil Durvalina P. O. Assis e professora do ensino superior na Universidade Norte do Paraná - Unopar. Possui graduação em Pedagogia pela Universidade Estadual de Londrina (2006) e mestrado em Educação pela da Universidade Estadual de Londrina (2011). É pesquisadora do grupo de pesquisa Filosofia, educação e condição humana da Universidade Estadual de Londrina. Tem experiência na área de Educação, com ênfase em Educação Infantil e Filosofia da Educação. Email: vivi.ed.infantil@gmail.com
} 


\section{Introdução}

A chamada pós-modernidade, termo expressamente ambíguo e vazio quando não devidamente discutido, como aponta Gallo (2006), encontra-se em um estado de tensão com o projeto da modernidade em uma postura de crítica e desconstrução das bases e do otimismo que a sustentam. Essa crítica pode se dar em uma perspectiva reacionária, na defesa e resgate de valores questionados pelo modernismo, como também na resistência à manutenção do status quo. O campo epistemológico, que é tomado como um dos aspectos centrais do projeto moderno, encontra-se no cerne das discussões que envolvem as temáticas e trazem implicações determinantes para a área da filosofia e dos processos de socialização, portanto, para a área da educação.

O pensador estadunidense Richard Rorty (1931-2007) tem sido considerado um importante representante do neopragmatismo e seus escritos e estudos trazem contribuições relevantes para esse debate e esclarecem pontos significativos para a reflexão sobre a produção cultural humana. Segundo Rorty (1994), essas reflexões e distinções são historicamente tratadas a partir de um projeto filosófico que é tradicionalmente idealista e platônico, o qual precisa ser combatido por ser puramente dualista e contraditório. Essas distinções também têm marcado o campo das ciências, da política, das artes e da moralidade juntamente com a filosofia, uma vez que dizem respeito às ferramentas que o homem pode fabricar para resolver seus problemas e contribuir para o progresso social.

Nesse sentido, este artigo tem por objetivo apresentar alguns aspectos da discussão feita pelo autor sobre a ideia de racionalidade e cultura e suas relações com os processos sociais/educativos na contemporaneidade que buscam alcançar laços de convivência mais harmônicos na interação entre as culturas, as artes e política contribuindo para o desenvolvimento e continuidade da sociedade humana.

\section{Cultura e Racionalidade: Há ou não uma superioridade cultural?}

Rorty discute as implicações de uma narrativa que "afirmam que determinadas culturas são mais racionais do que outras e, portanto, melhores" (RORTY, 2005, p. 77). O ponto de partida são as afirmativas de que há culturas mais racionalistas e/ou menos racionalistas, o que acaba por classificar as culturas em superiores e inferiores ou ainda em uma cultura melhor

\begin{tabular}{l|l|} 
Ano 10 & n. 22
\end{tabular}

Edição Especial, junho 2021

p. $116-133$ 
que a outra. $\mathrm{O}$ autor apresenta, então, três tipos de racionalidades para iniciar a discussão. No primeiro modelo, a narrativa racionalista gira em torno de afirmativas tais como:

\begin{abstract}
[...] que lulas têm mais [racionalidade] do que amebas, que seres humanos usuários de linguagem têm mais do que antropóides não usuários de linguagem, e que seres humanos armados com tecnologia moderna têm mais do que aqueles que não a possuem: a habilidade de enfrentar o meio ambiente, ajustando suas reações aos estímulos deste, de modo complexo e delicado (RORTY, 2005, p. 77).
\end{abstract}

Essa razão técnica ou capacidade de sobrevivência, segundo Rorty, é eticamente neutra, já que "sozinha, não ajuda a decidir a qual espécie ou qual cultura seria melhor pertencer" (RORTY, 2005, p. 77).

No segundo modelo de narrativa racionalista, a racionalidade é o ingrediente extra que faz o ser humano diferente do resto da natureza. Essa característica extra, pertencente ao ser humano, não está restrita à garantia de vida, à sobrevivência, podendo ser direcionada para outras finalidades. Ela possibilitaria mais que um ajustamento como "por exemplo, poder decidir que seria melhor morrer a fazer certas coisas” (RORTY, 2005, p. 78). Há hierarquias avaliativas e não simples ajustamento de meios aos fins aceitos.

No terceiro tipo ou modelo de racionalidade, essa é sinônimo de tolerância, de não agressividade, de se deparar com o diferente e não responder agressivamente diante dessas diferenças. Segundo Rorty, esse terceiro tipo de racionalidade é acompanhada de "um desejo de alternar os próprios hábitos - não somente de conseguir, mas do que anteriormente se queria, mas de se remodelar num diferente tipo de pessoa que quer coisas diferentes daquelas que se queria antes" (RORTY, 2005, p. 78).

Outra característica desse terceiro tipo de racionalidade é que ela está acompanhada de uma "confiança mais na persuasão do que na força, uma inclinação para conversar antes do que brigar, queimar ou banir." (RORTY, 2005, p. 78). Esse tipo de racionalidade inclina seus detentores a uma vivência coletiva, comunitária, na qual se vive e deixa os outros viverem e, agrupando novos modos desta forma de vida. Racionalidade dessa forma pode ser entendida como uma virtude, "como quase sinônimo de liberdade" (RORTY, 2005, p. 78).

Esse terceiro tipo de racionalidade é comumente misturado na tradição intelectual ocidental, pois: subentende que usamos linguagem e tecnologia para alcançar nossos desejos devido ao ingrediente extra que por sua vez falta nos outros animais. Também se assume que nossa capacidade de adaptação do primeiro tipo é a mesma? O tipo 1 de racionalidade (habilidade de enfrentar o meio ambiente, ajustando suas reações e estímulos de modo complexo e delicado) está identificado como a tolerância do tipo 3 de racionalidade. Ou seja,

\begin{tabular}{|c|c|c|c|c|}
\hline Qovista Dialectus & Ano 10 & n. 22 & Edição Especial, junho 2021 & p. $116-133$ \\
\hline
\end{tabular}


"quanto mais inteligentes somos para conseguir nos adaptar às circunstâncias, ampliamos o alcance e a complexidade de nossas respostas a estímulos, mais nos tornaremos tolerantes a outros tipos de seres humanos" (RORTY, 2005, p. 79).

Diante dessa junção dos três tipos de racionalidade, pode-se perceber que, de acordo com Rorty, os humanos bons em equipar-se tecnicamente para realizar seus desejos automaticamente adotariam desejos corretos, isto é, de acordo com a razão e, consequentemente serão tolerantes com aqueles que desejam coisas diferentes. No entanto, Rorty aponta razões filosóficas e políticas comuns para suspeitar dessa assimilação e suas implicações.

As razões filosóficas seriam aquelas apresentadas por Dewey e Derida, por exemplo, firma-se em combater a ideia de racionalidade como o ingrediente extra definido no tipo 2 de racionalidade. As razões políticas estão ligadas aos ideais de Roger Garaudy (19132012) e Ashis Nandy (1937-), que avalizam como doentes os países ocidentais e pelo próprio Rorty que pensa que embora os países do ocidente não estejam doentes, mas acuados, juntamente com o resto do mundo. Para os liberais que são pragmatistas como Rorty, afirma ele: "as questões sobre racionalidade e diferenças culturais se resumem a questões ligadas à relação entre racionalidade-1 e racionalidade-3, simplesmente descartamos a ideia de racionalidade-2" (RORTY, 2005, p. 79-80).

A racionalidade para Rorty está relacionada à adaptação e à disposição para vencer os problemas apresentados no contexto das dinâmicas sociais, distanciando-se do rigor argumentativo em busca de uma suposta verdade como a tradição filosófica vem colocando. A racionalidade colaboraria, não para almejar uma verdade absoluta, comum a todos, mas colaboraria com a perspectiva de alargar os laços de convivência mais harmônicos, pois embora os seres humanos tenham suas diferenças, todos eles pensam e sentem, relacionam-se de modos parecidos. Assim, a concepção de racionalidade de Rorty está ligada a um processo educativo, pois diz respeito aos nossos comportamentos perante nossos semelhantes e perante o meio social no qual nos encontramos.

Apos apresentar os três tipos de racionalidade Rorty apresenta também três definições para cultura. Na primeira definição, cultura é entendida como "um conjunto de hábitos de ação compartilhados" (RORTY, 2005, p. 80). Esses hábitos seriam aqueles que capacitam as pessoas de uma dada comunidade a se relacionarem de modo amistoso entre si. Desta forma, todo grupo tem sua peculiaridade, portanto sua própria cultura. Geralmente as pessoas pertencem a grupos diferentes, a culturas diferentes, neste sentido, Rorty afirma que a 


\section{CULTURA, RACIONALIDADE E POLÍTICA EM RICHARD RORTY... \\ Maria A. Lima Piai / Viviane Batista Carvalho}

cultura não é então "o nome de uma virtude, nem é necessariamente o nome de algo que, entre os animais, apenas seres humanos possui” (RORTY, 2005, p. 80).

No segundo sentido, cultura é apresentada por Rorty como uma virtude, como "alta cultura". Nessa definição, cultura é uma indicação de posse. É a posse da "habilidade de manipular ideias abstratas por simples prazer, e uma habilidade de discursar longamente sobre as diferenças de valores de tipo amplamente diverso, de pintura, música, arquitetura e literatura". Esse é o tipo de cultura que pode ser adquirida pelo processo educativo, geralmente disponibilizado ou direcionado aos grupos e indivíduos mais abastados da sociedade e isso implica também dizer, aos grupos mais desocupados. Esse tipo de cultura também está regularmente associado à racionalidade do tipo 3 (sinônimo de tolerância, de não agressividade, de se deparar com o diferente e não responder agressivamente diante dessas diferenças).

No seu terceiro sentido, cultura significa aquilo que é produzido pelo uso da racionalidade 2 (um ingrediente extra que faz o ser humano diferente do resto da natureza). Assim, a cultura estaria ligada a superação da animalidade bruta, irracional por "algo universalmente humano, algo que todas as pessoas e culturas são mais ou menos aptas a reconhecer e respeitar" (RORTY, 2005, p. 81).

O ponto levantado por Rorty é que, ao dizer que uma cultura, no sentido 1 (um conjunto de hábitos de ação compartilhados), "é mais 'avançada' que outra, significa que ela se aproximou mais da realização do 'essencialismo humano' do que outra cultura" (RORTY, 2005, p. 81). Essa ideia se expressa, segundo Rorty, naquilo que Hegel denominou consciência do espírito absoluto, uma universalização ou essencialismo.

As narrativas de respeito e proteção a todos os tipos de culturas são mencionadas geralmente como algumas ressalvas de que há alguns tipos de cultura que não deveriam existir, como por exemplo, a das gangues criminosas ou as de conluios de banqueiros internacionais, ou ainda culturas decadentes ou doentes que se encaixariam no sentido 1 (um conjunto de hábitos de ação compartilhados). Assim, Rorty coloca em xeque, esse discurso sugestivo de que toda cultura é merecedora de ser preservada.

Esse discurso está ligado à confusão feita entre os três sentidos de cultura que ele discute, essa sugestão está relacionada, segundo ele, ao fato de a cultura no sentido 1 (um conjunto de hábitos de ação compartilhados) estar relacionada à obra de arte, como no sentido 3 (aquilo que é produzido pelo uso da racionalidade). Uma espécie de triunfo da cultura 3 (aquilo que é produzido pelo uso da racionalidade) sobre a natureza. Se fracassássemos em apreciar e cultivar esses triunfos das culturas, seria um fracasso nosso, uma traição à cultura

\begin{tabular}{|l|l|l|l|l|} 
Q Rovista Dialectus & Ano 10 & n. 22 & Edição Especial, junho 2021 & p. 116 - 133 \\
\hline
\end{tabular}


nos seus sentidos 2 (uma virtude, habilidade de discursar e manipular ideias abstratas) e 3 (aquilo que é produzido pelo uso da racionalidade).

Essa "sugestão de que trataremos toda cultura como uma obra de arte prima facie merecedora de preservação como toda obra de arte é merecedora" (RORTY, 2005, p. 81) é, para Rorty, uma sugestão recente, característica dos tempos contemporâneos, sobretudo entre os intelectuais ocidentais de esquerda e está acompanhada por um sentimento de culpa em relação ao eurocentrismo "é certa raiva quanto à sugestão de que alguma cultura poderiam ser vista como menos "válida' do que outra" (RORTY, 2005, p. 82). Rorty desconstrói essa ideia, pois a entende como uma espécie de compensação. Para ele é uma tentativa de preservar a cultura enquanto dignidade humana, mesmo ela tendo perdido sua racionalidade 2 (um ingrediente extra que faz o ser humano diferente do resto da natureza). "É uma tentativa de recriar a distinção kantiana entre valor e dignidade por meio de se pensar a respeito de toda cultura humana, senão de todo indivíduo humano, como de valor incomensurável” (RORTY, 2005 , p. 82) como se envolvido pela aura que envolve a obra de arte para aqueles que concebem a cultura no sentido 2 (uma virtude, habilidade de discursar e manipular ideias abstratas.

Seguindo a analogia kantiana, Rorty afirma que essa versão não racionalista propõe a combinação da "afirmação de que toda a cultura é tão válida quanto qualquer outra afirmação de uma cultura-1" (um conjunto de hábitos de ação compartilhados) (RORTY, 2005, p. 82). Assim não seriam incoerentes afirmativas como: 'A cultura moderna ocidental é doente' ou 'Tudo bem ser canibal, foi uma prática cultural comum entre os tupinambás', ou 'O capitalismo é um câncer' ou, como no exemplo apresentado por Rorty na fala de Susan Sontag: 'A raça branca é o câncer do planeta'. A alternativa radical seria descartar tudo que é oriundo da cultura moderna ocidental, ou tudo certo se devorássemos uns aos outros, ou se matássemos seres humanos pertencentes à raça branca, ou ainda, a ingenuidade de que com o fim do capitalismo todos os problemas sociais, econômicos e políticos desapareceriam e as pessoas passariam a ser feliz em um estalar de dedos.

O que Rorty está pontuando é que no discurso contemporâneo intelectual de esquerda, muitas vezes transparece que somente "as culturas oprimidas são culturas-3 (aquilo que é produzido pelo uso da racionalidade) reais e validas" (RORTY, 2005, p. 83). Por outro lado há também intelectuais europeus modernos que tendem a valorizar exacerbadamente “obras de arte 'difíceis' e 'diferentes' - de preferências, produzida no sótão por artistas rejeitados e marginalizados" (RORTY, 2005, p. 83). Esse modelo seria exemplos válidos/reais da criatividade artística, e são, mas não só? Esse raciocínio exacerbado sugere que aquelas

\begin{tabular}{|c|c|c|c|c|}
\hline Qovista Dialectus & Ano 10 & n. 22 & Edição Especial, junho 2021 & p. $116-133$ \\
\hline
\end{tabular}


pinturas de arte acessíveis à compreensão do público e feitas por profissionais bem remunerados não possui valor criativo ou artístico, não alcança, portanto, uma posição de arte. Reduzia-se assim, a cultura e a arte dos povos colonizados e oprimidos como uma posição superior a outras formas de arte e cultura do ocidente contemporâneo ou pós-moderno.

Rorty está denunciando as ambiguidades que caracterizam a pós-modernidade ou contemporaneidade. Essa exaltação da cultura oprimida "como coisa mais preciosa do que qualquer outra feita pelo, ou, no ocidente contemporâneo" (RORTY, 2005, p. 83) vai ao encontro à visão da modernidade europeia de que "todas as formas de vida são 'infantis' em comparação à da Europa moderna" (RORTY, 2005, p. 83). Ou seja, essa “convicção baseia-se na ideia de que o próprio poder de suprimir outras formas de vida é uma indicação do valor das próprias formas" (RORTY, 2005, p. 83).

Rorty nos convida a observar as premissas. No exemplo da valoração da cultura ou arte dos oprimidos, o que torna a cultura preciosa é a ausência de poder, assim a debilidade e a pobreza seria um indicativo de valor, talvez ligada à ideia da pobreza de Cristo posta no ocidente. O que é uma premissa muito fraca do ponto de vista lógico. A tentativa neste caso parece ser a de "usurpar o espaço previamente ocupado por outro [...] o triunfo de uma cultura sobre a outra" (RORTY, 2005, p. 84). Uma tentativa de resolver um velho problema com a criação de novos problemas como colocou Dewey.

Rorty parece se nutrir da esperança de Dewey "de que a mesma ousadia experimental com a qual havíamos criado novos problemas como subprodutos, se combinada a uma vontade de diminuir o sofrimento, produzisse soluções graduais para esses novos problemas" (RORTY, 2005, p. 87).

A flexibilização, característica da pós-modernidade, pode ser associada tanto à liberdade quanto à opressão "tanto para ampliar o sofrimento quanto para diminuí-lo, tanto para fazer decrescer a racionalidade-3 quanto para ampliá-la" (RORTY, 2005, p. 87). Então, um maior ou menor grau de racionalidade no sentido 1 (habilidade de enfrentar o meio ambiente, ajustando suas reações aos estímulos deste, de modo complexo e delicado) não é uma premissa que garante a sua emancipação. Não há nada que antecede a experiência, não há um essencialismo segundo Rorty, pelo qual possamos ampliar nosso grau de racionalidade 3 (sinônimo de tolerância, de não agressividade, de se deparar como diferente e não responder agressivamente diante dessas diferenças).

As experiências são a realidade. A humanidade passou momentos de perseguição muito duros, como as perseguições religiosas que ocorreram no período medieval e, momentos

\begin{tabular}{|c|c|c|c|c|}
\hline Qevista Dialectus & Ano 10 & n. 22 & Edição Especial, junho 2021 & p. $116-133$ \\
\hline
\end{tabular}




\section{CULTURA, RACIONALIDADE E POLÍTICA EM RICHARD RORTY... \\ Maria A. Lima Piai / Viviane Batista Carvalho}

de mais tolerância religiosa, como ocorreu em alguns períodos da modernidade. Essas oscilações não estão ligadas a uma ideia de evolução histórica ou a de um essencialismo alcançado por meio de um processo educativo, mas pela experiência dos seres humanos naqueles contextos históricos e culturais de acordo com o que a realidade apresentava. Assim como Dewey, Rorty não está preocupado em fazer uma filosofia que forneça respaldo, fundamentos ou categorias estáveis que possibilitem avaliar hierarquicamente a cultura, a arte, etc.

Os seres humanos não seriam então uma classe especial, dotados de uma natureza humana, mas uma continuidade da natureza, em termos deweyanos, uma continuidade de amebas, dos antropoides que "imaginativamente mais flexíveis e livres poderiam ser nossos descendentes" (RORTY, 2005, p. 88).

Assim a social-democracia, apresentada por Dewey, poderia ser pensada como uma possibilidade na qual nossos descendentes, numa ideia de continuidade, que não estaria presa ao evolucionismo darwinista nem a ideia de busca de uma essência, causaria 'menos sofrimentos uns aos outros do que causa atualmente'. O que está posto nesse ideal deweyano, segundo Rorty, seria o "equilíbrio entre a minimização do sofrimento e a maximização da racionalidade-3" (RORTY, 2005, p. 88).

A minimização do sofrimento estaria colocada na ideia de tolerância com o diferente, na ideia de não ferir o outro. A maximização da racionalidade estaria colocada na ideia de não construir um estado dominador pan-óptico. Não haveria, então, uma reflexão desses habitantes, segundo Rorty, sobre si mesmos (um ingrediente extra que faz o ser humano diferente do resto da natureza), mas eles ouviriam como seres mais livres e felizes? que os pertencentes às comunidades e/ou sociedades que os antecederam.

A proposta desconstrutivista de Rorty é mostrar as implicações de propostas lineares. Assim, dentro dessa perspectiva deweyana de uma utopia social-democrata, Rorty levanta as seguintes provocações: As diferentes culturas geograficamente delimitadas em seus lugares atuais se manteriam ou seriam trituradas e/ou homogeneizadas? Se houvesse a homogeneização, isso seria um erro? Perderia algo irremediável? Ou será que se formariam novas diferenças culturais? Se novas diferenças se formassem espontaneamente nesse contexto de tolerância, compensaria as diferenças perdidas?

Rorty resgata com essas indagações que, embora não tenhamos uma resposta plausível para estas perguntas, continuamos a sustentar a necessidade de que as mais diversas culturas se mantenham vivas. Não há razões particulares para manter a esperança na

\begin{tabular}{|c|c|c|c|c|}
\hline Q Rovista Dialectus & Ano 10 & n. 22 & Edição Especial, junho 2021 & p. $116-133$ \\
\hline
\end{tabular}


imortalidade das diferenças culturais contemporâneas como também não há esperança de que essa diversidade possa ser superada por algo mais interessante.

Para Rorty o que fica é apenas um saudosismo, uma pouca importância que tende também a desaparecer. Segundo ele, lamentamos a perda de algumas espécies por sabermos que levaram milhões de anos para se constituírem, mas nada com muita implicância, as culturas empedradas do sentido 1 (um conjunto de hábitos de ação compartilhados) serão extirpadas "somente quando novas culturas de ao menos igual esplendor estivessem disponíveis para assumir seus lugares" (RORTY, 2005, p. 99), mesmo se houvesse paz, riqueza, sorte, racionalidade-3 (sinônimo de tolerância, de não agressividade, de se deparar como diferente e não responder agressivamente diante dessas diferenças) é utópico, pois a tolerância traz consigo a possiblidade de destruir as possibilidades de diferenças culturais.

\section{Aspectos Políticos em Rorty: O que temos em comum com os outros?}

Como resultado dos estudos feitos a partir dos escritos de Rorty é possível tratarmos alguns pontos no que concerne ao modo como o filósofo entende as questões ligadas à política e como esta deve ser organizada no meio social.

Assim como nos demais casos já apresentados anteriormente, Rorty apresenta os aspectos políticos de seu pensamento fazendo um paralelo entre vários pensadores, filósofos e estudiosos que trazem a baila esse tema. Dessa forma, ao tratarmos do campo político em Rorty vamos encontrar nomes como Dewey, Kuhn, Brandon, Wittgensteim, Kent, Habermas entre outros pensadores. Entretanto, é possível dizer que em grande parte as premissas de Dewey, James e Kuhn parecem estar bem presentes no que concerne a organização de uma política democrática, acrescentando-se a elas as ações que procuram exaltar aspectos como redistribuição de renda, a erradicação da fome e da miséria e a amenização ou mesmo extinção da crueldade e do sofrimento na convivência coletiva (ROTY, 2009). Para Jay Van Hook (1998, p. 8) a obra de Rorty está ligada, em grande parte, a interesses sociais e políticos, e isso fica evidente em seu livro em Contigência, ironia e solidariedade (2009).

Em seu livro Filosofia como política cultural (RORTY, 2009) o filósofo trabalha com a ideia de duas políticas que se intercruzam: a política real e a política cultural. A política real estaria vinculada aos aspectos práticos e econômicos do modo como a sociedade se organiza para o seu funcionamento. Baseada em ideais democráticos, a política real deve preocupar-se com assuntos reais e urgentes como a desigualdade financeira, o sofrimento

\begin{tabular}{|l|l|l|l|l|}
\hline Q Rovista Dialectus & Ano 10 & n. 22 & Edição Especial, junho 2021 & p.116 - 133 \\
\hline
\end{tabular}


humano, as injustiças sociais entre outros temas, criando estratégias que servirão como base para as instituições sociais colocarem em prática ações que contribuam para uma convivência coletiva mais adequada. Nesse campo há a busca por soluções para os diversos problemas que surgem na sociedade e que precisam ser sanados para o seu bom andamento.

Para ele é importante fazer a fusão entre o que é público e o que é privado, pois “o mais importante para cada um de nós é o que temos em comum com os outros." (RORTY, 2007, p. 15). Essa fusão teria uma visão ampliada da convivência entre os seres humanos e permitiria chegar a uma visão única em que concomitantemente existiria a "autocriação [vida autônoma] e a justiça, a perfeição privada e a solidariedade humana.” (RORTY, 2007, p. 17 - acréscimos nossos).

Já a política cultural, em termos mais amplos está ligada ao pensar sobre a política, ao debate que se faz sobre a utilidade, conveniência ou inconveniência de unir ou desunir um determinado aspecto de outro. Para ele, a política cultural "é a atividade humana menos governada por normas” (RORTY, 2009, p. 47). Pois, ela constitui um espaço de discussões das gerações, entre as tradições passadas e as novas configurações sociais, o que eleva o crescimento da cultura e também a transforma.

Segundo Rorty (2009) o termo política cultural está muito arraigado no uso correto das palavras e no modo de discutir (falar e pensar) sobre a organização social. As produções humanas sugerem novidades no modo como a sociedade se organiza em termos políticos e por isso mesmo é preciso "conversar" sobre o que fazer e como fazer, antes de efetivamente fazer algo. Nesse ponto Rorty trata de um aspecto muito importante de seu pensamento, a chamada “conversação" que está baseada nos pilares do diálogo, da narrativa, da redescrição e do uso do vocabulário.

Na conversação estarão abarcados os jogos de linguagem. Estes ocorrem quando um ser humano (ou grupo de pessoas) acaba por criar um novo vocabulário para expressar suas ideias com o intuito de deixar o discurso do outro (grupo) antiquado, e dessa forma apresentar e criar novas crenças que levarão a uma nova forma de organização social (modo de ver e fazer política). Mas, como isso funciona?

Para Rorty (2009) a capacidade da linguagem, de expressar, de criar novos termos é essencial para a divulgação de novas formas de pensamento e consequentemente para as mudanças na política real, pois dependendo da maneira como uma ideia é apresentada, esta poderá ou não ganhar novos adeptos, constituindo uma nova maneira de pensar, e quanto mais pessoas acreditam em suas ideias, mais cresce a "verdade" que se instala sobre isso, fazendo- 
se com que se amplie um determinado pensamento que passa a ser aceito e inserido no contexto social.

Dessa forma um político (pessoa que se ocupa da política), ao utilizar-se de práticas linguísticas mais adequadas, que sejam capazes de fazer com que outras pessoas apoiem as suas ideias, acaba criando "políticas" que se concretizarão de fato na política real evidenciada na sociedade, já que suas ideias serão aceitas pelos outros. "A política cultural não se restringe aos debates sobre os discursos [...]. Ela inclui também projetos para se livrar de tópicos inteiros do discurso." (RORTY, 2007, p. 20).

Nesse jogo das palavras, em que a "conversação" atrai adeptos e defensores de uma ideia enquanto outros são totalmente contrários a essa, ou apenas espectadores, muitos argumentos são levantados de um lado e de outro e aquele que melhor expuser seus contextos acabará por levar a cabo ações culturais, sociais e políticas que vão sendo modificadas e incorporadas ao modo de convivência coletiva. Assim, o ideal de um discurso é que ele seja capaz de justificar a crença nele contida a um público competente.

Há de se buscar uma coerência, um consenso e, nesse intuito, não há uma verdade absoluta, mas uma capacidade persuasiva. Numa sociedade democrática, não é coerente se pautar numa verdade indiscutível, mas buscar um modo de persuadir pessoas com a finalidade de aumentar o tamanho do grupo que aceita determinada justificativa e que apoia a crença defendida. Esse projeto persuasivo, para Rorty, não é somente relevante para a política democrática, é parte constituinte da política democrática (COOKE, 2004, p. 87).

Segundo Rorty (2007) na história humana muitas pessoa criaram novos discursos contestando antigas tradições, trazendo assim à baila novas formas de pensamento e de organização, como é o caso da escolha de parceiros para o casamento dos filhos por seus pais, prática comum a gerações passadas, ou mesmo para alguns países da atualidade. Nesse exemplo, algumas culturas que conseguiram retirar-se de tal prática o fizeram graças à contestação de muitos grupos. As verdades antes tidas como reais foram sendo substituídas por novas.

Atribuições de realidade ou verdade são [...] tributos que prestamos a entidades e crenças que se distinguiram, deram sua contribuição, demonstraram ser úteis e, portanto, foram incorporadas às práticas sociais aceitas. Quando essas práticas estão sendo contestadas, é inútil dizer que a realidade ou a verdade estão do lado de um dos contendores, pois tais alegações não passaram de estardalhaço e não contribuem seriamente para a política cultural (RORTY, 2007, p. 25).

\begin{tabular}{|l|l|l|l|l|}
\hline Qovista Dialectus & Ano 10 & n. 22 & Edição Especial, junho 2021 & p.116 - 133 \\
\hline
\end{tabular}


Nesse contexto, o talento de "falar de maneira diferente, e não para bem argumentar, é o principal instrumento de mudança cultural” (RORTY, 2007, p. 32). Ainda sobre esse ponto, o filósofo alerta para o fato de que todos devem ser livres para elaborar os "seus próprios jogos de linguagem, desde que não insistam em que todos também o joguem” (RORTY, 2007, p. 47).

Rorty (2009) salienta que o debate sobre as questões políticas concretas acabam por trazer mais felicidade para a humanidade como um todo do que muitos outros elementos presentes na vida humana, como a religião, por exemplo. Para ele, numa política democrática os diversos seguimentos com suas respectivas representatividades devem embrenhar-se numa "conversação" saudável e produtiva, pois esta acaba por criar uma sociedade mais justa, com maior redistribuição de renda e com maior acesso aos bens culturais, o que cria maior autonomia, emancipação e diminuição dos preconceitos.

Nesse ponto, os movimentos sociais são essenciais para a luta contra as diversas formas de opressão, entretanto é imprescindível que ao tomar certas diferenças nos discursos presentes nesses movimentos, estes sejam feitos a partir do que os seres humanos têm em comum e não sobre as diferenças entre eles. Do ponto de vista de Rorty ninguém deve ser discriminado por sua particularidade (vida privada), mas em termos de convivência coletiva a justiça se faz a partir da garantia da igualdade e da equidade.

A conversação, nesse caso seria a responsável por contribuir para a solução de problemas elevando aquilo que mais importa às pessoas. Numa sociedade democrática uma verdade seria obtida por meio de variados encontros livres e abertos em que se discute as formas políticas de se conduzir a sociedade, o que elevaria o grau de democracia para seu mais alto patamar.

Sobre essas discussões "livres e abertas" Rorty (2007) salienta que estas não estão livres de ideologias, todavia estão presentes quando várias instâncias sociais como a mídia, o campo judiciário, as universidades, ou até mesmo a mobilidade social conseguem "ouvir diferentes pessoas e pensar sobre o que elas dizem" (RORTY, 2007, p. 84).

Nesse caso o critério do que seria considerada a verdade passa pelo clivo de uma comunicação não distorcida. Em suas próprias palavras Rorty afirma: "não penso que haja muito o que dizer sobre o que conta como 'não distorcida', exceto o tipo que você obtém quando tem instituições políticas democráticas e as condições para fazer essas instituições funcionarem" (RORTY, 2007, p. 84).

\section{Reflexões e Relações com a Educação: Qual a função da educação?}

\begin{tabular}{|l|l|l|l|l|}
\hline Qovista Dialectus & Ano 10 & n. 22 & Edição Especial, junho 2021 & p.116 - 133 \\
\hline
\end{tabular}


A educação proposta por Rorty, ou mais especificamente falando, a sua filosofia da educação, está em grande parte envolvida em sua ideia sobre a "conversação" e no modo como encontramos novas maneiras de falar. Segundo Almeida e Vaz "a própria filosofia de Rorty é concebida como educação, ou melhor, como edificação: o projeto de encontrar modos novos, melhores, mais interessantes e fecundos de falar" (2013, p. 249).

Nesse sentido as ideias educacionais estão muito ligadas ao que seria tomado como "verdade" adotada por uma cultura, pois se educa conforme a crença que se pode justificar como verdadeira. Não há um conhecimento objetivo, pois a realidade muda conforme as "verdades" vão sendo assumidas. Para Rorty, a educação baseia-se na linguagem, pois é "impossível colocar-se entre a linguagem e o seu objeto, separar a girafa em si de nossa maneira de falar sobre a girafa" (RORTY, 1994, p. 127). Para ele os próprios objetos constituem artefatos da linguagem.

A formação do indivíduo estaria articulada no uso das normativas (linguagem), numa atitude filosófica em que a conversação está presente. A educação estaria em busca da verdade que contemplaria as diversas áreas do conhecimento não se permitindo aí a separação destes, mas a junção entre estes para um conhecimento único em que não há uma hierarquização entre as diversas áreas. Nesse ponto o filósofo prefere utilizar o termo "edificação" ao de “educação", pois este expressaria a ideia de um projeto mais amplo, pois:

\footnotetext{
A tentativa de edificar (a nós mesmos ou a outros) pode consistir na atividade hermenêutica de fazer conexões entre nossa própria cultura e alguma cultura exótica ou período histórico, ou entre nossa própria disciplina e outra disciplina que pareça perseguir objetivos incomensuráveis num vocabulário incomensurável. Mas pode, ao invés disso, consistir na atividade 'poética' de inventar novos objetivos, novas palavras ou novas disciplinas, seguidas, por assim dizer, pelo inverso da hermenêutica: a tentativa de reinterpretar nosso ambiente familiar nos termos não familiares de nossas novas invenções. Em qualquer caso, a atividade é (apesar da relação etimológica entre as duas palavras) edificante sem ser construtiva - pelo menos se 'construtivo' significa o tipo de cooperação na realização de programas de pesquisa que tem lugar no discurso normal. Pois o discurso edificante é suposto ser anormal, tirar-nos para fora de nossos velhos eus pelo poder da estranheza, para ajudar-nos a nos tornarmos novos seres (RORTY, 2007, p. 360).
}

Desse modo Rorty afirma que "do ponto de vista educacional, em oposição ao epistemológico e tecnológico, o modo como as coisas são ditas é mais importante do que a posse das verdades." (RORTY, 2007, p. 359). Nesse contexto propõe o método filosófico da redescrição que consistiria na capacidade de rejeitar as normas outrora estabelecidas pela linguagem e que a sustentavam, para propor novos caminhos, empreendendo novas narrativas que seriam resultantes do movimento entre as culturas e as pessoas.

\begin{tabular}{|l|l|l|l|l|}
\hline Qovista Dialectus & Ano 10 & n. 22 & Edição Especial, junho 2021 & p.116 - 133 \\
\hline
\end{tabular}


Este método seria essencial na educação, pois a partir dele haveria a possibilidade de se redescrever as coisas de muitas maneiras novas, proporcionando a possibilidade do abandono de discursos anteriores tidos como a posse da verdade em prol de um novo modo de pensamento que surge e que se propaga (RORTY, 2007). Para Silva, numa concepção educacional rortyana "é a partir da modificação de práticas linguísticas e, consequentemente, de outras práticas sociais que novos tipos de seres humanos são produzidos” (SILVA, 2012, p. $515)$.

Uma reforma se faz necessária, segundo Rorty, se pode colaborar para entender as questões cotidianas, proporcionar a compreensão das sutilezas do cotidiano e assim capacitar os indivíduos para a conversação, para a vida em sociedade, pois, deste modo, ampliaria a compreensão acerca dos anseios daqueles que estão no poder.

A educação teria então, a função de promover a solidariedade social. A cultura, por outro lado, auxiliaria na criação de novos valores e na esperança de que estes pudessem ser compartilhados, enquanto fossem nutridos pelas histórias comuns, pela vida em comunidade. A riqueza do processo educativo formal estaria na conversação entre professores e alunos (RORTY, 2007).

Para Rorty, a vida em sociedade requer solidariedade e essa solidariedade se faz com liberdade de expressão. Pois é por meio da conversação que a verdade se revela, não como algo mágico, divino ou absoluto, mas como resultado da socialização humana. Assim, o professor é um agente de socialização.

De acordo com Rorty, a educação colabora com a socialização (público) e a individualização (privado). A educação básica teria seu foco no processo de socialização, no exercício da cidadania, buscando promover a solidariedade, pois Rorty entende a solidariedade como um requisito para o exercício da cidadania. Um segundo nível da educação formal, o ensino superior, estaria mais focado na individualização, para o florescimento da imaginação e criatividade, com o intuito de autorrecriação, o que Rorty denomina de criatividade irônica.

Para Rorty a educação serve ao processo de socialização de toda a sociedade e ao processo de individualização ao promover a imaginação e criatividade. No entanto, ao traçar objetivos/enfoques para a educação básica e para a educação superior, Rorty nos cria um problema, já que é mais difícil o acesso ao ensino superior para um grupo considerável de pessoas dentro de diversas sociedades. Esse grupo sem acesso ao ensino superior estaria privado da formação mais focada no desenvolvimento da criatividade, da autocriação, da individualização. 
Uma alternativa viável seria pensar em um modelo educacional em que tanto a educação solidária do ensino básico como a educação ironista e criativa do ensino superior pudessem ser promovidas nos dois níveis de ensino, ou já no ensino básico. E, como afirma Jay Hook: "Talvez a função de socialização, predominante nos níveis básicos da educação, enquanto a irônica assuma precedência na educação superior. Mas, em algum grau, ambas as funções devem ser endereçadas para ambos os níveis” (HOOK, 1998, p. 17).

\section{Considerações finais}

Ao descartar a racionalidade - 2 (ingrediente extra que faz o ser humano diferente do resto da natureza), Rorty afasta-se do discurso racionalista que atribui aos seres humanos a capacidade inata de, diferentemente dos outros animais, realizar seus desejos e inventar tecnologias para realizar esses desejos. Os conceitos de racionalidade -1 (a habilidade de enfrentar o meio ambiente, ajustando suas reações aos estímulos deste, de modo complexo e delicado) e 3 (sinônimo de tolerância, de não agressividade, de se deparar como diferente e não responder agressivamente diante dessas diferenças) se destacam como úteis para a proposta pragmática de Rorty de firmar uma sociedade capaz de fundar-se na liberdade e na solidariedade.

Segundo ele, nenhuma cultura está protegida da extinção, nem mesmo o modo de vida dos animais não humanos. O mesmo Ocidente, no qual brotou o nazismo, também criou medicamentos, controle de doenças, vacinas, sistemas de saúde e sistemas educacionais. O ponto a ser discutido, segundo Rorty, não é mais a superioridade cultural, mas a capacidade de diferentes grupos humanos interagirem e criarem mecanismos que propiciem o seu desenvolvimento moral e intelectual recíprocos. Pois a violência é um tipo de formação cultural que pode deixar de existir, da mesma forma, como HIV e Covid-19 são vírus que podem ser dizimados.

A expectativa de Rorty é que a racionalidade -3 (sinônimo de tolerância, de não agressividade, de se deparar como diferente e não responder agressivamente diante dessas diferenças) possa minimizar o sofrimento humano e maximizar a solidariedade. Assim, a capacidade humana não é fruto de um inatismo, mas da adaptabilidade e flexibilidade das relações humanas, desta forma, as práticas e instituições sociais vão ficando cada vez mais complexas. Rorty, assim como Dewey, acredita que a solução dos problemas humanos se resolve a partir do surgimento de novos problemas.

A racionalidade -1 (a habilidade de enfrentar o meio ambiente, ajustando suas reações aos estímulos deste, de modo complexo e delicado) não garante a eliminação das

\begin{tabular}{|l|l|l|l|l|}
\hline Qevista Qialectus & Ano 10 & n. 22 & Edição Especial, junho 2021 & p. 116 - 133 \\
\hline
\end{tabular}


injustiças e da crueldade. A interação humana gerou flexibilidade e essa flexibilidade possibilitou a criação/invenção das instituições sociais e essas podem ser totalitárias ou democráticas, egoístas ou solidárias, tolerantes ou opressoras e, tanto uma como a outra, são práticas elaboradas pelas pessoas em suas interações na sociedade. Então, qual o caminho proposto por Rorty? A resposta estaria em uma educação/socialização que perseguisse a tolerância e a criatividade, que estivesse aberta ao diálogo com o intuito de buscar criatividade e formas mais solidárias de viver.

Essas novas formas de viver é que enterrariam ou não as formas de organização social criadas pelas sociedades humanas ao longo da história da humanidade. O diálogo proporcionaria a superação de antigos valores e modos de vida, abrindo espaços para o novo, no entanto, isso não significa esquecer a história e as tradições, já que é por meio delas que os sujeitos se reconhecem como tais. O sujeito se constitui a partir da liberdade. E a liberdade é que permite ao ser humano dar novos significados a suas experiências e construir novos caminhos para a vida em sociedade, instituindo novos hábitos e valores, favorecendo o surgimento do novo que se impõe ou que passa a ser mais facilmente percebido e aceito.

Os discursos relacionados às questões culturais, para Rorty, no atual momento, são soluções provisórias. Uma utopia global. A filosofia é entendida como crítica à cultura. Voltemos então à nossa questão inicial: Há ou não uma superioridade cultural? A resposta de Rorty é: não. Pois, a evolução apresentada na filosofia pós-moderna, inclusive na filosofia dele, não termina com a proposta de uma sociedade globalmente homogeneizada. Mas em novas formas culturais heterogêneas, criadas conforme a dinâmica social e a história não liner, que estariam atreladas a uma ideia de razão intersubjetiva.

Para Rorty, o que o filósofo dos dias atuais deveria se empenhar para realizar, seria dar continuidade ao diálogo por meio de sugestões que possibilitassem certo consenso acerca dos problemas da realidade e das transformações culturais que garantissem um certo progresso, uma continuidade.

A interação entre cultura, arte e política contribuiria para o desenvolvimento da filosofia e da sociedade segundo Rorty, e ele, inclusive, busca isso em sua filosofia. Sem um campo delimitado, a filosofia estaria pronta para atender às necessidades culturais que se impõem de modo cada vez mais acentuado, plural e democrático. Assim, filosofia, ciência, arte e moral colaborariam mutuamente para o desenvolvimento de cada uma dessas áreas, e estas se apresentariam como áreas ou facetas distintas da cultura, não tendo qualquer uma delas uma precedência ou maior importância do que as outras.

\begin{tabular}{|c|c|c|c|c|}
\hline Qevista Dialectus & Ano 10 & n. 22 & Edição Especial, junho 2021 & p. $116-133$ \\
\hline
\end{tabular}


A filosofia contemporânea é, para Rorty, uma continuação, em um sentido mais otimista, um melhoramento dos caminhos (como nos apontamentos de Hegel). A filosofia nos é apresentada como uma reflexão acerca da cultura. Daí a importância da narrativa/conversação para que a filosofia seja entendida como eles propôs: uma forma de crítica cultural ou de política cultural.

A educação teria como função dois processos, o de socialização (público) e o de individualização (privado), sendo que o processo de socialização precisaria ocorrer antes do processo de individualização. É preciso propor uma educação que visasse a construção de uma sociedade voltada para a formação da democracia, para a prática da liberdade e para a solidariedade humana, esta última inclusive, seria estritamente necessária para a edificação de uma sociedade mais justa e igualitária. Ou seja, as práticas de linguagem (conversação) deveriam sempre se voltar para discussões profícuas que tomassem a política, a justiça social, a liberdade e a imersão nos bens culturais como algo a que todas as pessoas deveriam ter acesso.

\section{Referências bibliográficas}

ALMEIDA, Felipe Quintão; VAZ, Alexandre Fernandez. Educação e realidade, Porto Alegre, v. 38, n. 1, p. 249-270, jan./mar. 2013.

COOKE, Elisabeth F. Rorty on Conversation as an Achievement of Hope. In: Contemporary Pragmatism. vol. 1, n.1, p. 83-102, June. 2004.

GALLO, Silvio. Modernidade/pós-modernidade: tensões e repercussões na produção de conhecimento em educação. Educação e Pesquisa, São Paulo, v.32, n.3, p. 551-565, set./dez. 2006.

HOOK, Jay M. Van. Cavernas, cânones e o professor ironista na filosofia da educação de Richard Rorty. Trad. de Paulo Ghiraldelli Jr. In: Filosofia, sociedade e educação. Ano 2. n. 2, p. 7-18, Marília, 1998.

RORTY, Richard. Contingência, ironia e solidariedade. Trad. Vera Ribeiro. São Paulo: Martins Fontes, 2007.

Filosofia como política cultural. Trad. João Carlos Pijnappel. São Paulo: Martins Fontes, 2009.

Pragmatismo e política. Trad. Paulo Ghiraldelli Jr. São Paulo: Martins Fontes, 2005. (Coleção dialética).

Relativismo: Encontrar e Fabricar. In: CICERO, Antonio; SALOMÃO, Waly. Banco Nacional de Ideias: O Relativismo enquanto Visão de Mundo. Concepção e Curadoria. Trad. Claudia Cavalcanti e Eliana Sabino. Rio de Janeiro: Francisco Alves, 1994.

\begin{tabular}{|c|c|c|c|c|}
\hline Q Rovista Dialectus & Ano 10 & n. 22 & Edição Especial, junho 2021 & p. $116-133$ \\
\hline
\end{tabular}


SILVA, Heraldo Aparecido. A filosofia da educação de Richard Rorty: epistemologia, conversação, redescrições, narrativas e as funções da educação. Educação e filosofia. Uberlândia, v. 26, n. 52, p. 509-526, jul./dez. 2012. 